\title{
CAP-Gly Domain-Containing Linker Protein 1
}

National Cancer Institute

\section{Source}

National Cancer Institute. CAP-Gly Domain-Containing Linker Protein 1. NCI Thesaurus. Code $C 84466$.

CAP-Gly domain-containing linker protein 1 (1427 aa, 161 kDa) is encoded by the human CLIP1 gene. This protein plays a role in both centrosome formation and endocytosis. 